Metals Analysis Results for the Structural Qualification Test Series (SQTS) 01 - 05.

David Zalk

May 17, 2006 
This document was prepared as an account of work sponsored by an agency of the United States Government. Neither the United States Government nor the University of California nor any of their employees, makes any warranty, express or implied, or assumes any legal liability or responsibility for the accuracy, completeness, or usefulness of any information, apparatus, product, or process disclosed, or represents that its use would not infringe privately owned rights. Reference herein to any specific commercial product, process, or service by trade name, trademark, manufacturer, or otherwise, does not necessarily constitute or imply its endorsement, recommendation, or favoring by the United States Government or the University of California. The views and opinions of authors expressed herein do not necessarily state or reflect those of the United States Government or the University of California, and shall not be used for advertising or product endorsement purposes.

This work was performed under the auspices of the U.S. Department of Energy by University of California, Lawrence Livermore National Laboratory under Contract W-7405-Eng-48. 
HAZARDS CONTROL DEPARTMENT ES\&H Team 1

June 27, 2001

ES\&H 1-01-056
TO:

FROM:

SUBJECT:
Kent Haslam, Albert Lee, Jack Lowry, and Rick Visoria

Enclosed is the report summarizing the metals analysis results at the Contained Firing Facility (CFF), during SQTS $01-05$. This metals analysis includes evaluation of a bulk dust and surface swipe sampling protocol during the testing series that obtained samples at 3 primary locations in the CFF chamber area. The sampling protocol for each of the bulk dust samples involves an assessment of the concentration for 20 different metals, the oxidation state of selected metals, a particle size selective analysis, and morphological information. In addition, surface swipes were taken during SQTS 05 on the equipment and personnel door frames to indicate the characteristics of airborne metals due to leakage past the gasket seals. The bulk dust metals analysis indicates a nearly complete conversion of the aluminum casing to an oxide form with an even split between spherical and non-spherical morphology. Size selective analysis shows $83 \%$ of the particulates are in the inhalable size range of less than 100 microns and $46 \%$ are in the respirable range of less than 10 microns. Combining metals analysis and leakage results indicate the potential for a problematic personal exposure to metals external to the chamber unless modifications are made. Please feel free to call me at 2-8904 if you have any questions or if I may be of further service.

$\begin{array}{lr}\text { cc: Jerry Bardecker } & \text { L-871 } \\ \text { Carl Ingram } & \text { L-170 } \\ \text { Jim Lyle } & \text { L-874 } \\ \text { Lloyd Multhauf } & \text { L-170 } \\ \text { Dewey Ravenscroft } & \text { L-874 } \\ \text { Larry Sedlacek } & \text { L-871 } \\ \text { Larry Simmons } & \text { L-871 } \\ \text { Mark Sueksdorf } & \text { L-871 }\end{array}$

University of California 


\section{METALS ANALYSIS RESULTS \\ FOR THE \\ STRUCTURAL QUALIFICATION TEST SERIES 01 - 05}

At

Site 300

Building 801

Contained Firing Facility

Prepared for:

Kent Haslam, Albert Lee, Jack Lowry, and Rick Visoria

Site 300

Lawrence Livermore National Laboratory

Prepared by:

David Zalk

2-8904

June 27, 2001 


\title{
METALS ANALYSIS RESULTS \\ FOR THE \\ STRUCTURAL QUALIFICATION TEST SERIES 01 - 05
}

\author{
ABSTRACT \\ Industrial Hygienist: $\quad$ David M. Zalk, MPH, CIH \\ Facility: \\ Building 801, \\ Contained Firing Facility \\ Dates: \\ March 27 - April 26, 2001
}

\section{GENERAL FINDINGS:}

Bulk dust samples and surface swipe samples were taken from March 27 through April 26, 2001 at the Contained Firing Facility (CFF) firing chamber area during the Structural Qualification Test Series (SQTS) 01 through 05. The sampling protocol includes an assessment of the concentration for 20 different metals, the oxidation state of selected metals, a particle size selective analysis, and morphology.

Bulk Dusts; The bulk dust metals analysis indicates a nearly complete conversion of the aluminum casing to an oxide form and the creation of a variety of aluminum-containing compounds. Morphological information is available for SQTS $02-05$ and it indicates an even split in the creation of spherical and non-spherical particulates. Size selective analysis for the entire test series shows $82.7 \%$ of the particulates are in the inhalable size range of less than 100 microns and $46.3 \%$ of the particulates are in the respirable range of less than 10 microns.

Surface Swipes; Surface swipe samples were taken after SQTS 05 on both the equipment door and personnel door frames to indicate the characteristics of airborne metals that leaked past the gasket seals. A mean of $88.4 \%$ of the particulates on the door frames were of a non-spherical morphology which indicates leakage quickly after shot time. The personnel door frame also had 6 times more particulates larger than 100 microns in width then did the equipment door, reflecting well on efforts to improve the equipment door seal.

Combined Analyses; Previous carbon monoxide monitoring indicates a leak potential at five locations. Metals analysis results show that virtually all metals within the chamber, even trace levels as alloys or residuals on the chamber surfaces, can be accounted for in the dust analyses and therefore may be present wherever leaks may occur as both airborne and surface particulate. Preliminary estimates indicate that approximately 10 milligrams of beryllium, per each kilogram of mass within the 
Metals Analysis Results

UCRL-TR-221448

for SQTS 01 - 05

$-4-$

June 27, 2001

chamber, may lead to personal exposures during personnel door re-entry procedures above the $0.2 \mu \mathrm{g} / \mathrm{m}^{3}$ Action Level for beryllium. 


\subsection{Introduction}

After each test of the Structural Qualification Test Series (SQTS) at the Contained Firing Facility (CFF), there was a debriefing session. After SQTS 03 the Industrial Hygienist for CFF was tasked with performing and assessing a complete metals analysis on bulk dust samples that had already been taken, and a similar assessment for bulk dust samples that would be taken for the remainder of the SQTS. The sampling protocol for each of the bulk dust samples involves combined assessment methods for the concentration of 20 different metals, the oxidation state of selected metals, a particle size selective analysis, and obtaining morphological information. In addition, surface swipe sampling was performed during SQTS 05 on the equipment and personnel door frames to indicate the characteristics of airborne metals due to leakage past the gasket seals. The SQTS was also an opportunity to obtain other information covered in previous reports, such as area and personal sampling for airborne metals ${ }^{1-6}$ and the potential for leakage at various locations external to the CFF chamber ${ }^{1}$.

The metals analysis protocol includes a determination of the distribution of the dust and debris created by each of the tests. It was determined that the three best sampling locations to determine size distribution would be based on the dust's heaviest to lightest fractions. The heaviest fraction was presumed to be the dust remaining on the chamber floor after each shot. The lightest fraction was best reflected as the dust collected on a pre-filter surface as long as each sampled pre-filter was dedicated to one individual test. The dust that settled on horizontal surfaces on the chamber walls, such as the bolts on the inside of the equipment door, served as the collection area for the medium weight fraction. Previous metals evaluations occurred to determine the potential for personal exposures and the efficiency of the ventilation within the chamber determined in earlier personal sampling reports ${ }^{1-5}$.

\subsection{Operational Description}

Hazards Control ES\&H Team 1 employees, Ron Cadiz, Jeff DeBisschop, and David Zalk collected bulk dust samples and surface swipe samples from March 27 through April 26, 2001. The bulk dust sampling was performed at various locations in and around the CFF firing chamber located in Building 801 (B-801). Bulk dust sampling was systematically collected, when possible, from the chamber floor, the upstream side of a pre-filter dedicated to an individual test, and from the horizontal surfaces of bolts on the inside of the equipment door. Additional bulk dust samples were taken from the camera room, after a leak in a gasket during SQTS 03 or 04 became apparent, and from the collection bag of a chamber floor vacuum after SQTS 02. Surface swipe sampling was performed during SQTS 05 on the hinge and open side of the equipment door and on the open side of the personnel door frames. These surface samples were taken of a 
white, powdery residue that formed across the inside frame of the door and past the gasket seal. These surface swipe samples were taken to indicate the characteristics of airborne metals due to leakage past the gasket seals. This metals analysis sampling protocol occurred during the five experiments that were part of the originally scheduled SQTS.

The SQTS for the Contained Firing Facility (CFF) chamber included five planned experiments. The five experiments had different amounts of C-4 explosive in an aluminum casing. The first experiment, SQTS 01, contained 15 Kilograms $(\mathrm{Kg})$ of C-4 and occurred on March 26, 2001. SQTS 02 had $30 \mathrm{Kg}$ of C-4 and occurred on April $3^{\text {rd }}$. SQTS 03 had $60 \mathrm{Kg}$ of C-4 and occurred on April 11 $1^{\text {th }}$. SQTS 04 had $75 \mathrm{Kg}$ of C-4 (125\% overtest of the operational limit) and occurred on April 19 th $^{\text {th }}$ SQTS 05 had $35 \mathrm{Kg}$ of C-4 and occurred on April 26 $6^{\text {th }}$. The experiments for SQTS 01 through 04 were placed in the middle of the chamber at a point 4 feet above the chamber floor. Both the location and size of SQTS 05 were the most indicative of future testing with the experiment placed in front of the FXR target on the beam center line.

The bulk dust samples were taken the day following a test when possible. Chamber floor samples were taken at random locations on the north side. Pre-filter samples were taken after the removal of a single pre-filter dedicated to an individual test and were taken from the upstream side in the center of the filter. Equipment door bulk samples were taken from a powdery gray dust that settled on the top horizontal surface of twelve bolts facing the chamber side of the equipment door at a height of approximately four feet above the chamber floor. The camera room bulk sample was taken after SQTS 05, but the bulk dust sampled was shaken loose from a previous leak in a gasket around a portal that occurred during SQTS 03 and possibly SQTS 04. The surface swipe samples were taken, over an area of approximately 100 square centimeters, of a white, powdery residue that formed across the inside frame of the equipment and personnel door frames and across their gasket seals. The locations of all bulk dust samples, surface swipe samples, as well as area and personal sampling for metals, are outlined within the map listed as Attachment A at the end of this report.

\subsection{Sampling and Analytical Methodologies}

Metals analysis was performed on the bulk dust samples by digesting the samples using the Environmental Protection Agency (EPA) SW-846 Method 3050A and analyzing for 20 metals using EPA SW-846 Method 6010A. Sample analysis for these metals was by Inductively Coupled Argon Plasma - Atomic Emission Spectrometry (ICP-AES) and was performed by the LLNL Hazards Control Analytical Laboratory, an American Industrial Hygiene Association (AIHA) accredited laboratory. This method is considered semi-quantitative, but is essential for analyzing aluminum in the presence of all the other Industrial Hygiene series of metals sampled. The one environmental sample for metals within a digested pre-filter was sampled according to the Total Threshold Limit Concentration (TTLC) metals analysis by the EPA SW-846 Method 
3050A, then analyzed for metals with Method 6010A. Analysis for mercury was performed in accordance with Method 7471A by the LLNL C\&MS Environmental Services, accreditated by the Environmental Laboratory Accreditation Program (ELAP).

For the analysis of bulk dust and surface swipe samples, particle characterization, size distribution, and morphology was performed with Scanning Electron Microscopy (SEM). A portion of each sample was mounted on a conductive carbon tab on an SEM stub. To minimize extraneous peaks, the samples were not coated. Each sample was analyzed in the SEM at $20 \mathrm{kV}$ accelerating voltage and a magnification of $100-2500$ times. Elemental compositions were determined using energy dispersive $\mathrm{x}$-ray spectroscopy (EDX) which can detect elements from boron (atomic number 5) and up in concentrations above approximately 0.5 percent. Laboratory analysis was performed by Forensic Analytical, an American Industrial Hygiene Association (AIHA) accredited laboratory.

For area monitoring of the Industrial Hygiene series of metals ${ }^{1}$, SKC air sampling pumps were used for the personal sampling with cassettes in line pre-calibrated at 2.0 liters per minute $(1 / \mathrm{min})$ with a precision rotameter previously calibrated against a primary standard. Cassettes were 37 millimeter, 0.8 micron pore size, mixed cellulose ester fiber (MCEF) filter and were connected inline with Tygon tubing. A post-survey flow rate was performed to check for change in sampling rate due to build-up on the cassette filter. Sample analysis for IH metals was by Inductively Coupled Argon Plasma - Atomic Emission Spectrometry (ICP-AES) utilizing NIOSH Method 7300. The analysis was performed by the LLNL Hazards Control Analytical Laboratory, an American Industrial Hygiene Association (AIHA) accredited laboratory.

\subsection{Results}

This section is divided into three parts to reflect the three different types of sampling methods used to obtain metals analysis information. The three different sampling methods, reflecting the three parts of this section, are bulk dust analysis, surface swipe analysis, and airborne dust analysis. The first part of this section on bulk dust analysis begins with the metals concentrations for 20 different metals across SQTS 01 - 05 which are listed in Table 1. The particle size selective analysis begins in Table 2 showing a graphic representation for the bulk dust, divided into four different Industrial Hygienerelated size categories, across SQTS $01-05$. Morphology of the bulk dust, as well as some identified oxidation states for certain metals and compounds are presented.

The information presented in Table 3 through Table 9 is in the form of percentages. Each compound listed is shown as a percentage composition of its original sample constituents. Therefore Tables 3 - 9 may have a grouping of percentages that do not add up to hundred, this is because there are other compounds within the same sample that constitute its total composition. Table 3 
shows the fate of aluminum and aluminum oxide and its morphological state, representing a particle being seen as either spherical or non-spherical. Table 4 shows additional spherical/non-spherical compound concentrations and Table 5 lists other non-spherical compounds. The next sub-section combines the data from SQTS $02-05$ to show more detail regarding the size selective information for aluminum oxide as either spherical (Table 6) or non-spherical (Table 7) particulates. Pictures from some of the SEM analysis protocol are included for your viewing pleasure and include the images used determining this combined data for the chamber floor after SQTS 04 and 05.

Surface swipe sampling results are from SQTS 05 and were taken on the hinge and open side of the equipment door and on the open side of the personnel door frames. Results that detail aluminum oxide size selective information as spherical aluminum oxide are in Table 8 and non-spherical in Table 9. Airborne monitoring is then presented and is divided into area and personal sampling efforts discussed in previous reports ${ }^{1,5,6}$. Results for area monitoring of the Industrial Hygiene series of metals taken at the hinge side of the equipment door, and at 15 feet away, are presented in Table 10. Table 11 shows personal breathing zone metals results at the personnel door during re-entry for SQTS 04 and SQTS 05. Locations of bulk dust samples, surface swipe samples, as well as area and personal sampling for metals, are outlined within the map listed as Attachment A at the end of this report. 
UCRL-TR-221448

\subsection{Results; Bulk Dust}

\subsubsection{Metals Concentration}

\section{TABLE 1; Metals Concentrations for Bulk Dust Samples}

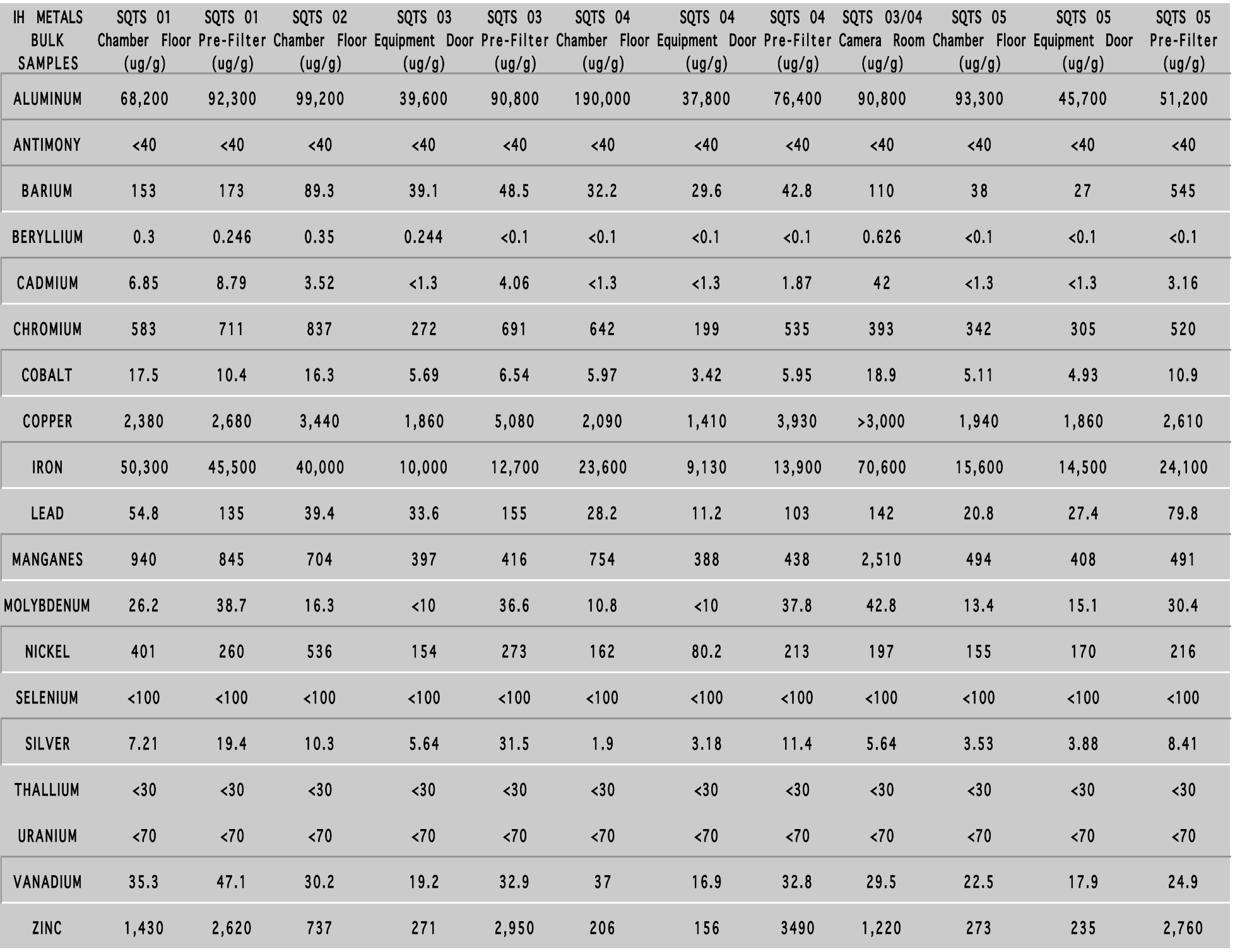


Metals Analysis Results

for SQTS 01 - 05
UCRL-TR-221448

June 27, 2001

\subsubsection{Particle Size Selective Analysis (SQTS 01 - 05)}

TABLE 2; Bulk Dust - Size Selective Analysis

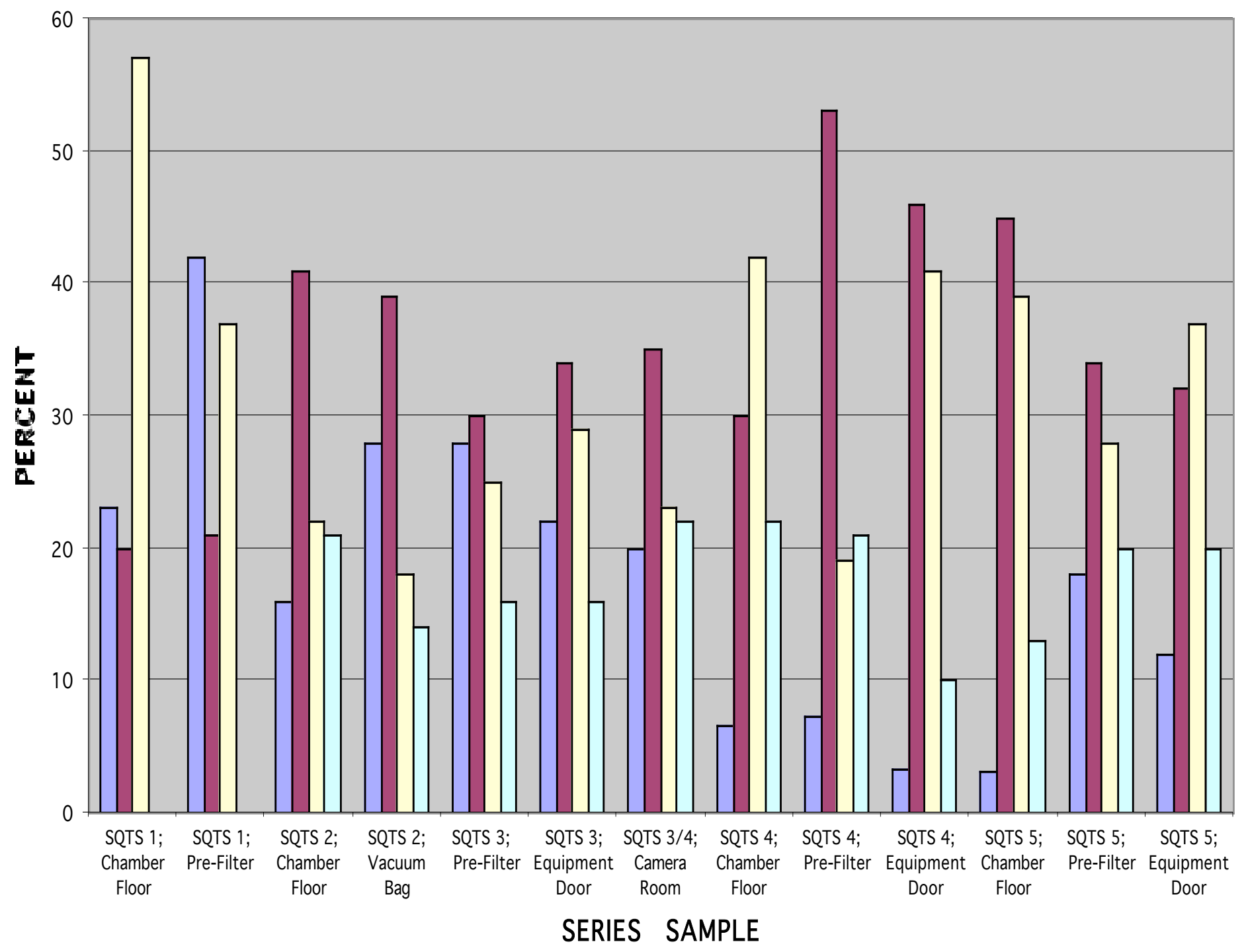

$\square>100$ microns $\square 100-10$ microns $\square 10-1$ microns $\square<1$ micron 


\subsubsection{Morphology And Oxidation States (SQTS 01 - 05)}

TABLE 3; Aluminum morphology \& Oxidation States*

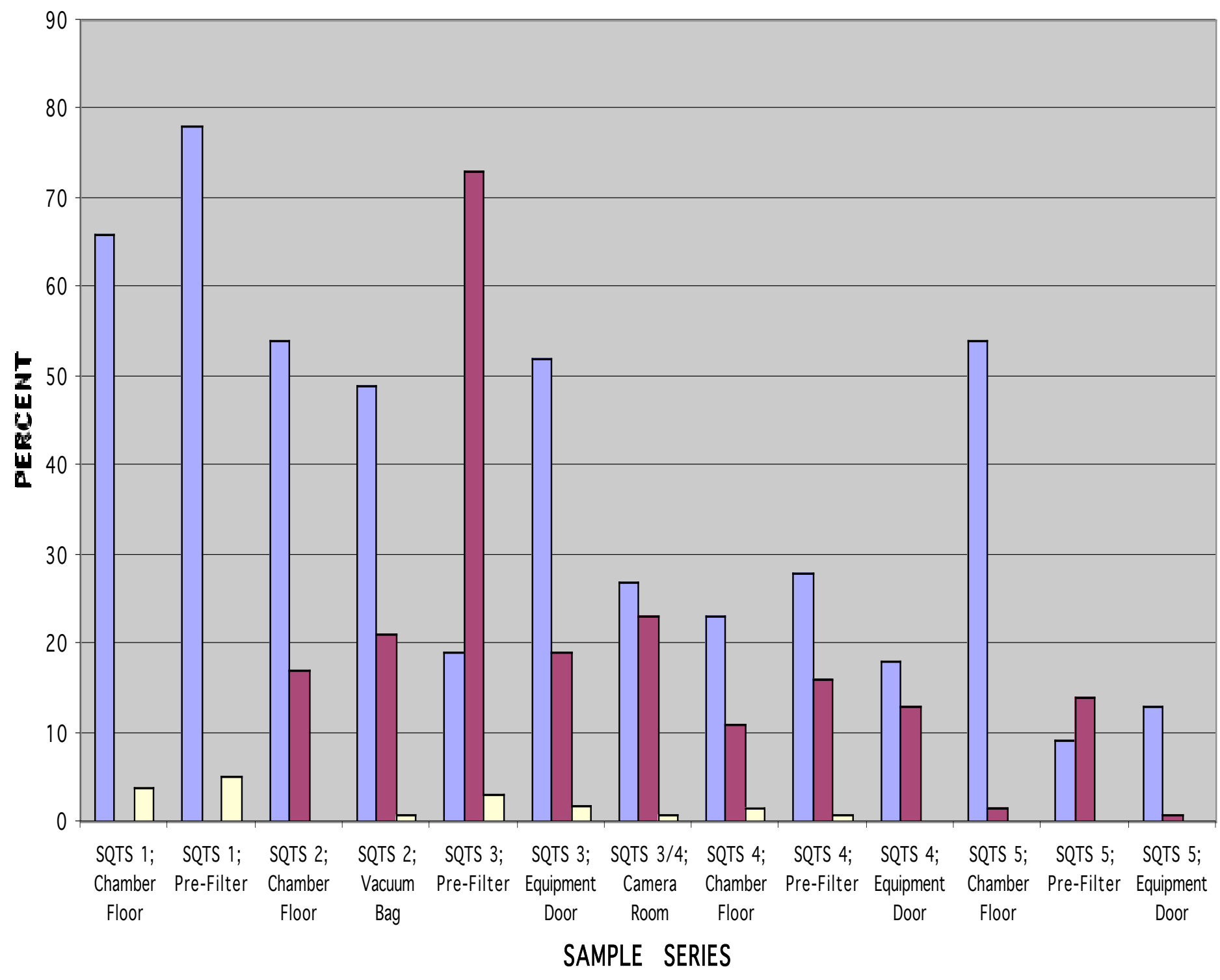

\section{$\square$ Al-0 Spherical $\square$ Al-0 Non-Spherical $\square$ Al Non-Spherical}

* Each compound is shown as a percentage distribution within its own dust sample. 
TABLE 4; Other Compounds and Their Morphology**

\begin{tabular}{|lccccccc}
$\begin{array}{c}\text { BULK } \\
\text { SAMPLE }\end{array}$ & $\begin{array}{c}\text { Al-Si-Ca-Fe-O Al-Si-Ca-Fe-0 } \\
\text { INFORMATION }\end{array}$ & $\begin{array}{c}\text { Spherical-Ti-Fe-0 } \\
(\%)\end{array}$ & $\begin{array}{c}\text { Non-Spherical-Si-Ti-Fe-0 } \\
(\%)\end{array}$ & $\begin{array}{c}\text { Spherical } \\
(\%)\end{array}$ & $\begin{array}{c}\text { Al-Fe-O } \\
\text { Non-Spherical } \\
(\%)\end{array}$ & $\begin{array}{c}\text { Al-Fe-0 } \\
(\%)\end{array}$ & $\begin{array}{c}\text { Non-Spherical } \\
(\%)\end{array}$ \\
\hline SQTS 1; Chamber Floor & 16 & $*$ & 6.3 & $*$ & 0 & 0 \\
\hline SQTS 1; Pre-Filter & 4.1 & $*$ & 1.5 & $*$ & 0 & 0 \\
\hline SQTS 2; Chamber Floor & 6.3 & 7.8 & 4.7 & 7 & 0 & 0 \\
\hline SQTS 2; Vacuum Bag & 0.7 & 1.4 & 2.8 & 9.9 & 0 & 0.7 \\
\hline SQTS 3; Pre-Filter & 0 & 0 & 0.5 & 1.5 & 0 & 0 \\
\hline SQTS 3; Equipment Door & 0 & 0 & 17 & 0 & 0 & 3.5 \\
\hline SQTS 3/4; Camera Room & 5.2 & 17 & 5.2 & 7 & 0 & 10 \\
\hline SQTS 4; Chamber Floor & 15 & 11 & 10 & 3.3 & 20 & 0 \\
\hline SQTS 4; Pre-Filter & 2.9 & 8.8 & 12 & 7.3 & 0 & 19 \\
\hline SQTS 4; Equipment Door & 17 & 14 & 19 & 10 & 0 & 0 \\
\hline SQTS 5; Chamber Floor & 3.2 & 0.8 & 4 & 4.8 & 0 & 25 \\
\hline SQTS 5; Pre-Filter & 11 & 25 & 7.2 & 9.9 & 2 & 15 \\
\hline SQTS 5; Equipment Door & 1.7 & 5 & 13 & 9.2 & 26 & 30 \\
\hline
\end{tabular}

* Not Determined for SQTS 01 Samples

** Each compound is shown as a percentage distribution within its own dust sample. 
TABLE 5; More Non-Spherical Compounds*

\begin{tabular}{|c|c|c|c|c|c|c|c|c|}
\hline $\begin{array}{l}\text { BULK SAMPLE } \\
\text { INFORMATION }\end{array}$ & $\begin{array}{l}\mathrm{Si}-0 \\
(\%)\end{array}$ & $\begin{array}{c}\text { Al-Ca-0 } \\
(\%)\end{array}$ & $\begin{array}{l}\mathrm{Fe}-0 \\
(\%)\end{array}$ & $\begin{array}{c}\mathrm{Si}-\mathrm{Al}-0 \\
(\%)\end{array}$ & $\begin{array}{c}\text { Cu-Al-0 } \\
(\%)\end{array}$ & $\begin{array}{c}\mathrm{AI}-\mathrm{Cl}-0 \\
(\%)\end{array}$ & $\begin{array}{c}\mathrm{Al}-\mathrm{Si}-\mathrm{Ca} \\
(\%)\end{array}$ & $\begin{array}{c}0 \mathrm{Al}-\mathrm{Ca}-\mathrm{Fe}-0 \\
(\%)\end{array}$ \\
\hline SQTS 1; Chamber Floor & 0.6 & 2 & 0.6 & 3 & 1.2 & 0 & 0 & 0 \\
\hline SQTS 1; Pre-Filter & 1 & 0.52 & 0 & 7.3 & 0 & 0 & 0 & 0 \\
\hline SQTS 2; Chamber Floor & 0 & 0 & 0 & 2.3 & 0 & 0 & 0 & 0.78 \\
\hline SQTS 2; Vacuum Bag & 0 & 0 & 0 & 13 & 0 & 0 & 0 & 0 \\
\hline SQTS 3; Pre-Filter & 0 & 0 & 0 & 3 & 0 & 0 & 0 & 0 \\
\hline SQTS 3; Equipment Door & 0 & 0 & 0 & 2.6 & 0 & 1.7 & 2.6 & 0 \\
\hline SQTS 3/4; Camera Room & 0 & 0.87 & 2.6 & 1.7 & 0 & 0 & 0 & 0 \\
\hline SQTS 4; Chamber Floor & 0 & 0 & 0.55 & 4.4 & 0 & 0 & 0 & 0 \\
\hline SQTS 4; Pre-Filter & 0 & 0.73 & 0 & 4.4 & 0 & 0 & 0 & 0 \\
\hline SQTS 4; Equipment Door & 0 & 0 & 0 & 6.7 & 0 & 2.2 & 0 & 0 \\
\hline SQTS 5; Chamber Floor & 0 & 0.8 & 0.8 & 4.8 & 0 & 0 & 0 & 0 \\
\hline SQTS 5; Pre-Filter & 0 & 0.66 & 0 & 5.3 & 0 & 0 & 0 & 0 \\
\hline SQTS 5; Equipment Door & 0 & 0 & 0.55 & 4.4 & 0 & 0 & 0 & 0 \\
\hline
\end{tabular}

* Each compound is shown as a percentage distribution within its own dust sample. 


\subsubsection{Combined Aluminum Information (SQTS 02 - 05)}

TABLE 6; Size Selective; Spherical Aluminum Oxide *

* Each compound is shown as a percentage distribution within its own dust sample.

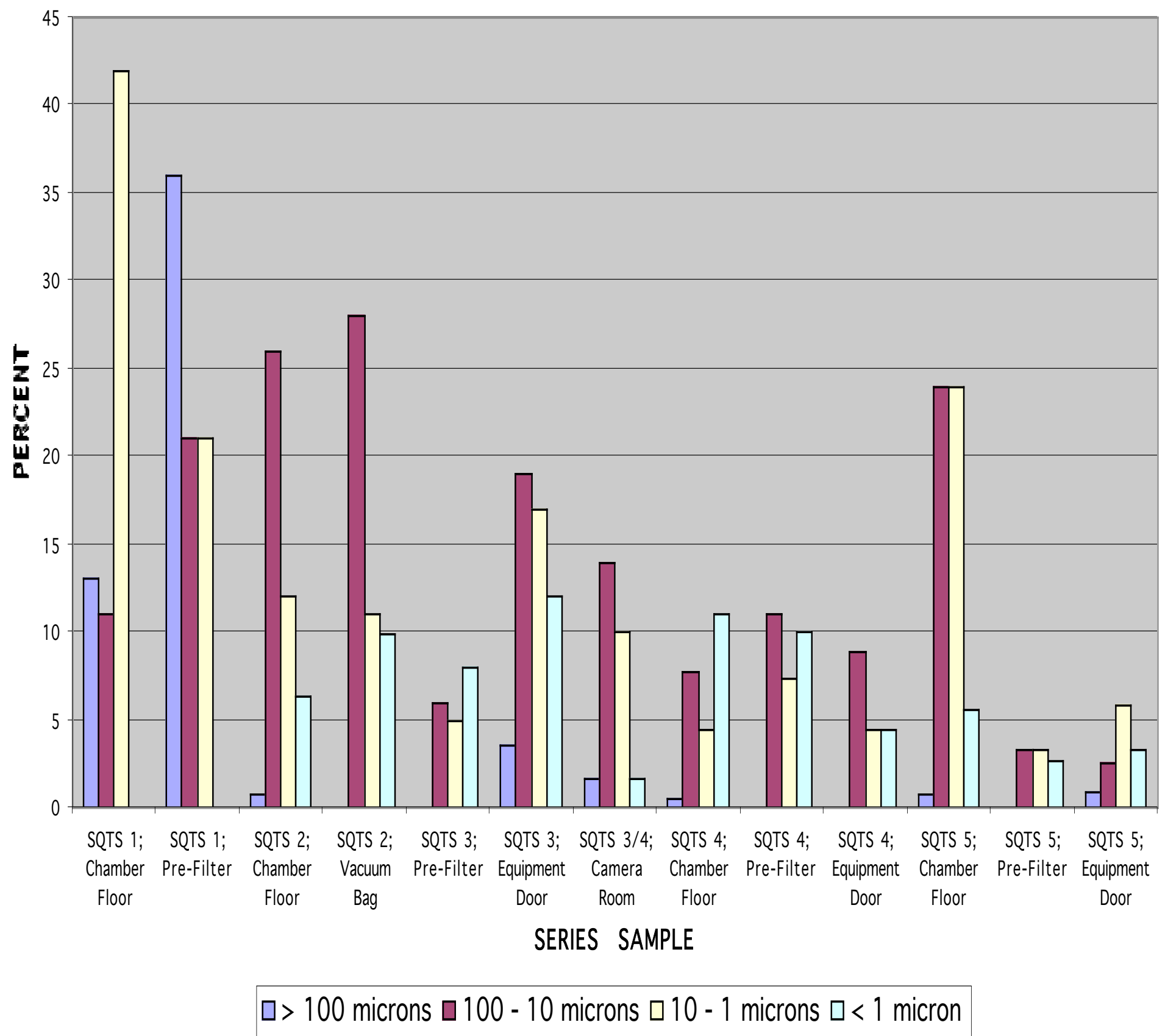


TABLE 7; Size Selective; Non-Spherical Aluminum Oxide*

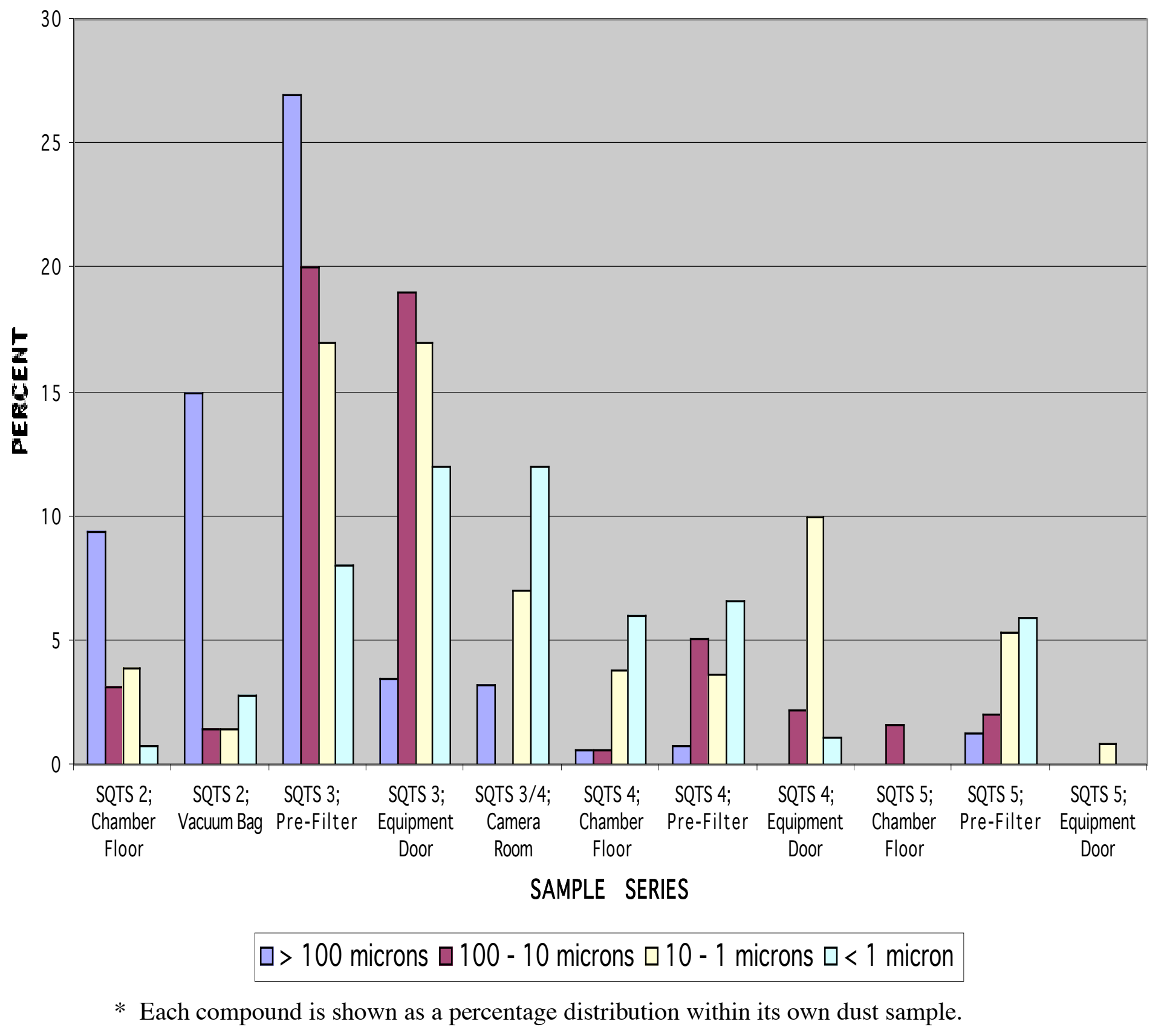


Metals Analysis Results for SQTS 01 - 05

\subsubsection{SEM Pictures Used to Derive Combined Information}

Picture 1; Chamber Floor SQTS 04

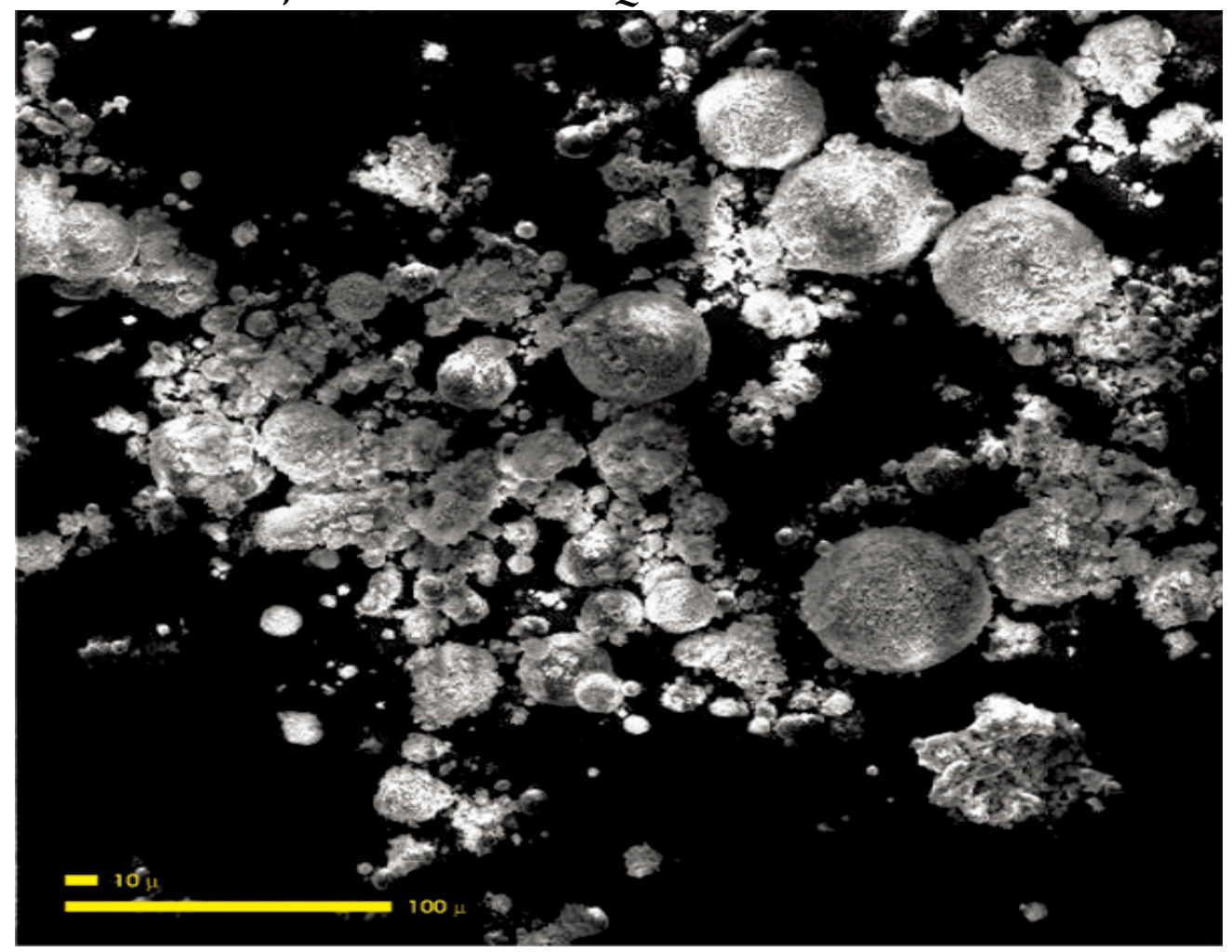

Picture 2; Chamber Floor SQTS 05

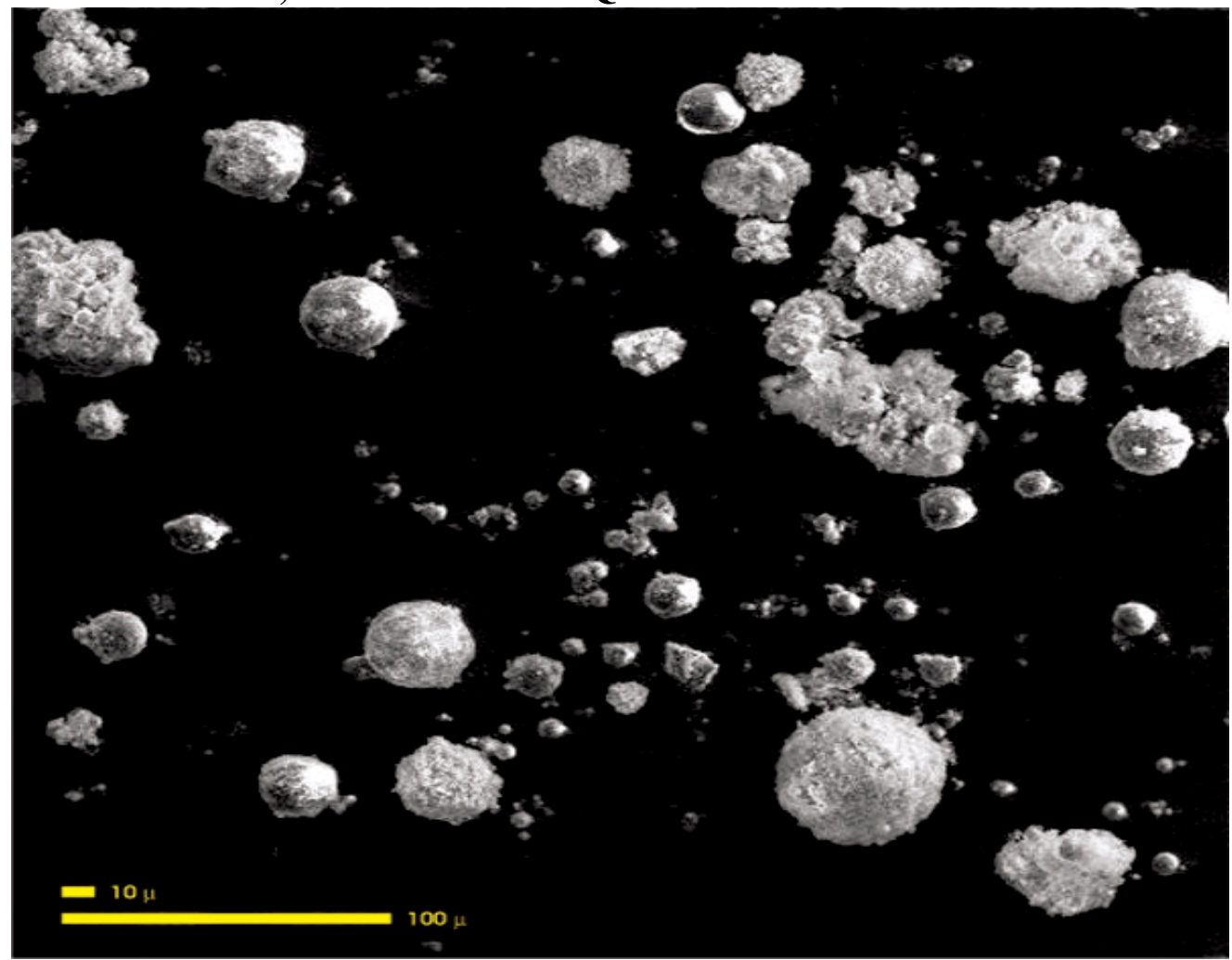




\subsection{Results; Surface Swipes}

\subsubsection{Combined Aluminum Information (SQTS 05)}

TABLE 8; Size Selective; Spherical Aluminum Oxide*

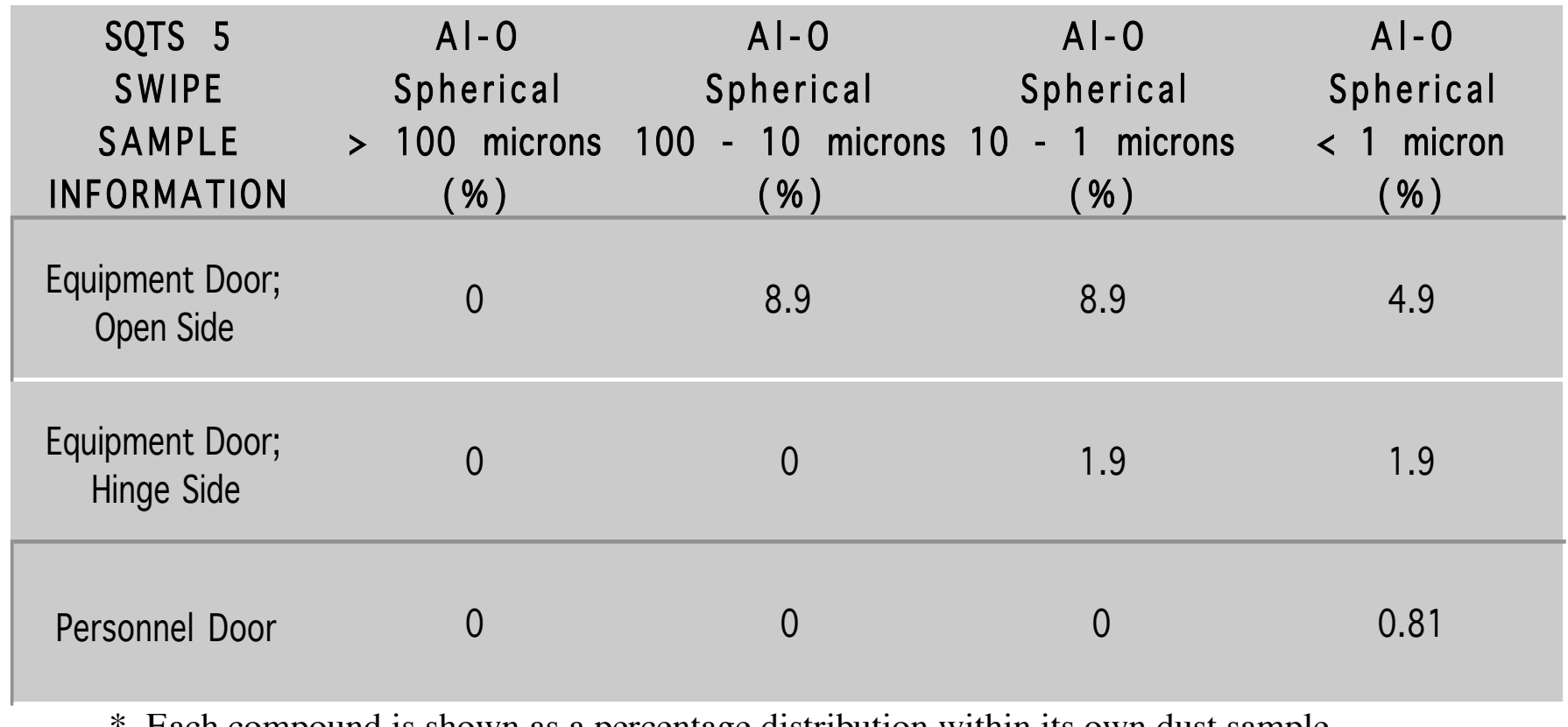

* Each compound is shown as a percentage distribution within its own dust sample.

TABLE 9; Size Selective; Non-Spherical Aluminum Oxide*

\begin{tabular}{|c|c|c|c|c|}
\hline $\begin{array}{c}\text { SQTS } 5 \\
\text { SWIPE } \\
\text { SAMPLE } \\
\text { INFORMATION }\end{array}$ & $\begin{array}{c}\text { Al-0 } \\
\text { Non-Spherical } \\
>100 \text { microns } \\
(\%)\end{array}$ & $\begin{array}{c}\text { Al-0 } \\
\text { Non-Spherical } \\
100-10 \text { microns } \\
(\%)\end{array}$ & $\begin{array}{c}\text { Al-0 } \\
\text { Non-Spherical } \\
10-1 \text { microns } \\
(\%)\end{array}$ & $\begin{array}{c}\text { Al-0 } \\
\text { Non-Spherical } \\
<1 \text { micron } \\
(\%)\end{array}$ \\
\hline $\begin{array}{l}\text { Equipment Door; } \\
\text { Open Side }\end{array}$ & 1.6 & 11 & 28 & 11 \\
\hline $\begin{array}{l}\text { Equipment Door; } \\
\text { Hinge Side }\end{array}$ & 0 & 0 & 26 & 1.8 \\
\hline Personnel Door & 11 & 12 & 24 & 25 \\
\hline
\end{tabular}

* Each compound is shown as a percentage distribution within its own dust sample. 


\subsection{Airborne Metals}

\subsubsection{Area Metals (SQTS $04-05)$}

TABLE 10; Area Metal s at Hinge Side of the Equipment Door for SQTS 4 and 5

\begin{tabular}{|ccccc|} 
Metals & $\begin{array}{c}\text { SQTS 4 } \\
\text { At Door } \\
(u g / m 3) *\end{array}$ & $\begin{array}{c}\text { SQTS } 4 \\
\text { At 15 Feet } \\
(u g / m 3)\end{array}$ & $\begin{array}{c}\text { SQTS 5 } 5 \\
\text { At Door } \\
(u g / m 3)\end{array}$ & $\begin{array}{c}\text { SQTS 5 15 Feet } \\
(\mathrm{ug} / \mathrm{m} 3)\end{array}$ \\
\hline Aluminum & 226 & 74.7 & & \\
\hline Copper & 10.7 & 4.43 & & \\
\hline Iron & 37.1 & 13.9 & 10.2 & 2.86 \\
\hline Manganese & 0.953 & 0.411 & & \\
\hline
\end{tabular}

${ }^{*} \mu \mathrm{g} / \mathrm{m}^{3}=$ micrograms of metal per cubic meter of air.

4.3.2 Personal Metals (SQTS 04 - 05)

TABLE 11; Breathing Zone Metals Results at Personnel Door During Re-Entry for SQTS 04 and SQTS 05

\begin{tabular}{|ccccc} 
Metals & $\begin{array}{c}\text { Employee 1 } \\
\text { SQTS 4 } \\
(\mathrm{ug} / \mathrm{m} 3)\end{array}$ & $\begin{array}{c}\text { Employee 2 2 } \\
\text { SQTS 4 } \\
(\mathrm{ug} / \mathrm{m} 3)\end{array}$ & $\begin{array}{c}\text { Employee } \\
\text { SQTS 5 } \\
(\mathrm{ug} / \mathrm{m} 3)\end{array}$ & $\begin{array}{c}\text { Employee 2 } \\
\text { SQTS 5 } \\
(\mathrm{ug} / \mathrm{m} 3)\end{array}$ \\
\hline Aluminum & 33.8 & 78.6 & 57.1 & 34.3 \\
\hline Copper & 2.03 & 3.54 & 2.03 & 1.69 \\
\hline Iron & 7.07 & 14.4 & 11.1 & 10.2 \\
\hline Manganese & & 0.34 & & \\
\hline
\end{tabular}




\subsection{Discussion}

The intention of this report is to gain as much information as possible from the SQTS to develop some insight for potential Industrial Hygiene-related concerns for the use of beryllium within the CFF chamber. It must first be noted that the information discussed in this report is based on aluminum being the primary mass weight of metal within the CFF chamber. It is acknowledged that there is a considerable difficulty when comparing aluminum to beryllium. Beryllium is one third the weight of aluminum and has a melting point about twice as high. Finally divided aluminum dust is easily ignited which can add to the heat of reaction which may render difficulty in creating analogies to beryllium. This information is problematic when considering beryllium's ability to holds its shape over a wide temperature range, its brittle nature, its high heatabsorption capacity, and that it is about six times stiffer than steel. Beryllium is similar to aluminum within the CFF chamber environment in that its chemical properties are such that they are both metals resistant to attack by acid due to the formation of a thin oxide film. Comparison becomes even more problematic when it is considered that there is relatively little or no information on the particle characterization of beryllium within an explosive test environment, especially when performed indoors.

\subsection{Bulk Dust}

The bulk dust metals analysis indicates a nearly complete conversion of the aluminum casing to an oxide form and the creation of a variety of aluminum-containing compounds. The higher than expected heat of combustion due to aluminum dust's ignitability within the chamber may have accounted for this conversion being more complete than expected. The cumulative information is summarized in Table 12 below. Table 12 reflects the percentages across all the bulk dust samples for general morphology and size selective information. Morphological information is available for SQTS $02-05$ and it indicates an even split in the creation of both spherical and nonspherical particulates. Size selective analysis for the entire test series shows $83 \%$ of the particulates are in the inhalable size range of less than 100 microns and $46 \%$ of the particulates are in the respirable range of less than 10 microns. The inhalable mass fraction is considered to be the size range within which airborne particulates can enter into the human respiratory system. The respirable mass fraction is the size range that allows airborne particulate to enter the alveolar region of the lungs where scarring is most likely to occur.

The size selective information across all bulk dust samples indicate that $46 \%$ of the particulates are less than 10 microns and $37 \%$ of the particulates are within the 10 to 100 micron size range. This is important to consider in light of the Industrial Hygiene personal sampling protocol. The current beryllium standard within the LLNL Chronic Beryllium Disease Prevention Program, calls for the use of a Total Dust sample cassette which is not size selective and can not be correlated with size specific information. The 
current version of the ACGIH Threshold Limit Values (TLV) for Chemical Substances ${ }^{7}$ has beryllium on its Notice of Intended Changes with an 8-hour Time Weighted

Average of $0.1 \mu \mathrm{g} / \mathrm{m}^{3}$ taken as an inhalable sample. Other occupational exposure limit setting bodies are considering sampling for beryllium in the respirable fraction only.

\section{TABLE 12; Cumulative Results; As Percentages Across All Bulk Dust Samples}

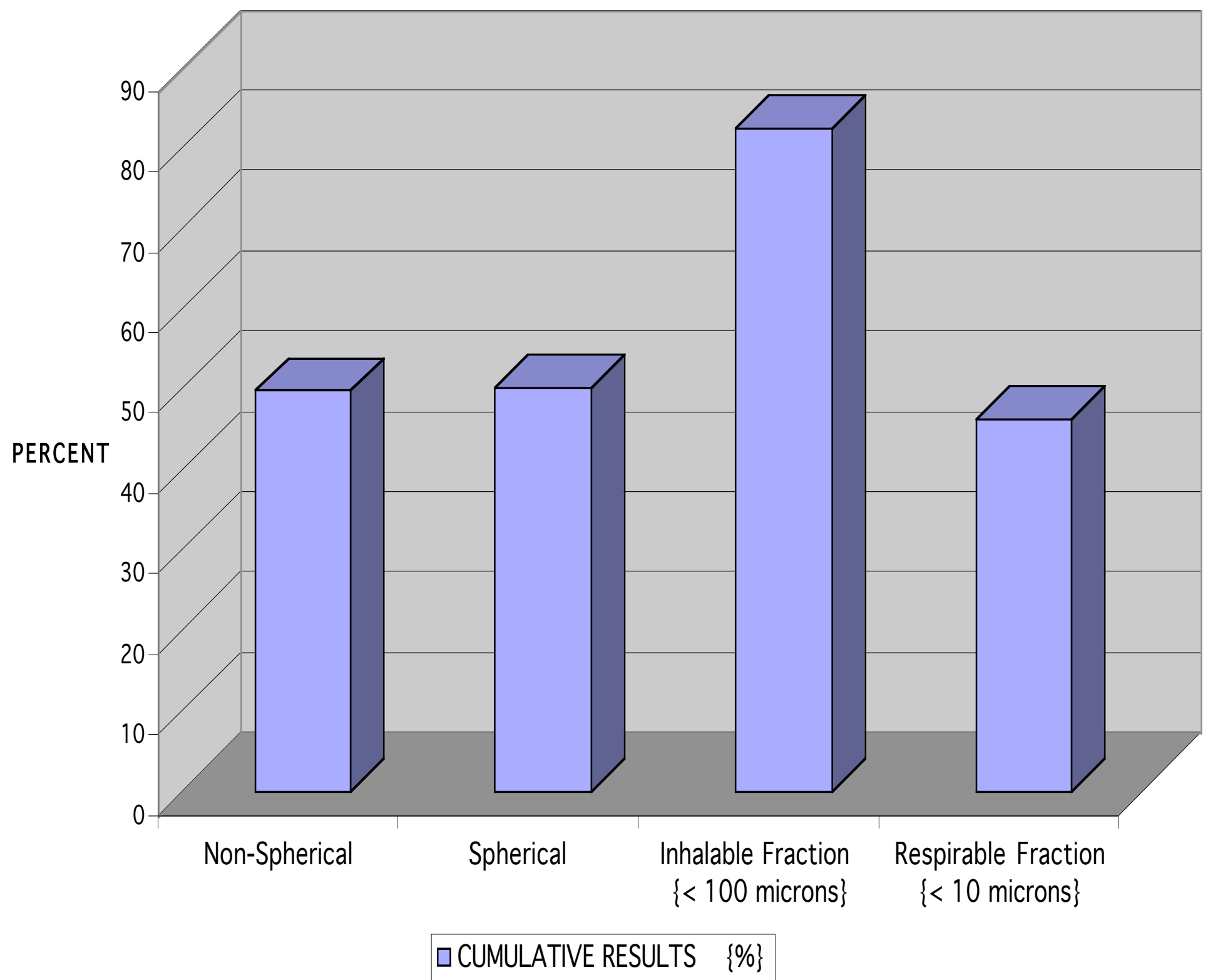

When particulates in the inhalable size range are captured on a personal sampling cassette, there is an increase in weight of the sample collected which may be 
problematic for low occupational exposure values for toxic chemicals, such as beryllium's current $0.2 \mu \mathrm{g} / \mathrm{m}^{3}$ Action Level. Alternatively, although particulates in the respirable size range will weigh less as collected, they will remain in the air much longer than larger particulate. This is especially true for low density elements like beryllium. To better understand this concept it is important to discuss the terminal settling velocity of particulates which is reflected in the following equation ${ }^{8}$ :

$$
\begin{gathered}
\mathrm{V}_{\mathrm{TS}}=\left(\rho_{P}\right)\left(d^{2}\right)(g) / 18 \eta \quad \text { for } d>1 \mu \mathrm{m}, \\
\mathrm{V}_{\mathrm{TS}}=\text { Terminal Settling Velocity }(\mathrm{cm} / \mathrm{s}) \\
\rho_{P}=\text { Density of the Particle }\left(\mathrm{g} / \mathrm{cm}^{3}\right) \\
d=\text { Diameter of Sphere }(\mathrm{cm}) \\
\mathrm{g}=\text { Acceleration of Gravity }\left(\mathrm{cm} / \mathrm{s}^{2}\right) \\
\eta=\text { Gas Viscosity }(\mathrm{g} / \mathrm{cm}-\mathrm{s})
\end{gathered}
$$

Terminal settling velocity increases rapidly with particle size, being proportional to the square of particle diameter. A simpler version of this equation, valid only for unitdensity spheres at standard conditions is:

$$
\mathrm{V}_{\mathrm{TS}} \approx 0.003\left(d^{2}\right) \quad \text { for } 1<d<100 \mu \mathrm{m}
$$

Therefore, the relative size of the particulates available to become airborne becomes extremely important in determining the potential for it to be collected on a personal sampling cassette. The larger sizes may settle quicker, however more mass will be collected on a given cassette. The smaller sizes may not weigh as much on collection, however they have a much greater chance of staying airborne for a longer period of time. Since the density of beryllium is approximately three times less than aluminum, even larger beryllium-containing particulates will have a greater chance of remaining airborne longer than aluminum-containing particulates. This simplified approach breaks down somewhat with consideration for morphology and other environmental factors, however more research into this area is necessary before more specifics can be realistically added to the equation.

\subsubsection{Possible Metal Sources (SQTS 01 - 05)}

Virtually all of the elements within the CFF chamber can be accounted for. It is the source of these elements that may be put into question. It has become apparent that all of the test apparatus constituents be considered. Also to be considered is not only the residual layers of dirt and debris that accumulate on the chamber surfaces, but also materials used on the surfaces of the chamber. This includes the paint used to coat the 
chamber floors and walls. Residual environmental surface levels of beryllium and cadmium, for example, seem to be flushed out of the chamber after SQTS 03. An attempt to account for these sources is presented below in Table 14 and include information from Table 1 and during calibration for these results as well, and

environmental digestion of a pre-filter Total Threshold Limit Concentrations (TTLC) for metals presented in Table 13.

TABLE 13

\begin{tabular}{|c|c|}
\hline PRE-FILTER METALS & TOTAL THRESHOLD LIMIT \\
\hline ENVIRONMENTAL ANALYSIS & CONCENTRATION VALUES $(\mathrm{mg} / \mathrm{kg})$ \\
\hline Antimony & 3.3 \\
\hline Arsenic & $<1.6$ \\
\hline Barium & 65.7 \\
\hline Beryllium & 2.2 \\
\hline Cadmium & 2.3 \\
\hline Chromium & 122 \\
\hline Cobalt & 2.6 \\
\hline Copper & 334 \\
\hline Lead & 35.1 \\
\hline Manganese & 126 \\
\hline Mercury & 24.2 \\
\hline Molybdenum & 3.9 \\
\hline Nickel & 43.4 \\
\hline Potassium & 575 \\
\hline Selenium & $<1.5$ \\
\hline Silver & 2.7 \\
\hline Strontium & 454 \\
\hline Thallium & $<4.4$ \\
\hline Vanadium & 18.8 \\
\hline Zinc & 729 \\
\hline
\end{tabular}




\section{TABLE 14}

\begin{tabular}{|c|c|c|}
\hline BULK DUST & ANALYSES & POTENTIAL \\
\hline Aluminum & & Casing and Shot Stand \\
\hline Antimony & ** & Below a High Limit of Detection (40 ug/g) \\
\hline Arsenic & & Below a High Limit of Detection (50 ug/g) \\
\hline Barium & & Experimental Assembly \\
\hline Beryllium & & $\begin{array}{c}\text { Environmental Background, Bullnose Surface. Flushed Out } \\
\text { After SQTS } 03\end{array}$ \\
\hline Cadmium & & Environmental Background. Flushed Out After SQTS 03 \\
\hline Calcium*, & ** & Environmental Background, Concrete \\
\hline Chromium & & $\begin{array}{c}\text { Stainless Steel Wires Used for Seismic Restraint, } \\
\text { Aluminum Alloy }\end{array}$ \\
\hline Cobalt & & Experimental Assembly \\
\hline Copper & & $\begin{array}{c}\text { Stainless Steel Wires Used for Seismic Restraint, } \\
\text { Aluminum Alloy }\end{array}$ \\
\hline Iron & & Nuts, bolts, screws, washers \\
\hline Lead & & Experimental Assembly, Lead/Tin Solder \\
\hline Lithium** & & $\begin{array}{c}\text { Environmental Background, Possible Historical Bullnose } \\
\text { Surface }\end{array}$ \\
\hline Magnesium & & Aluminum Alloy \\
\hline Manganese & & Stainless Steel and Aluminum Alloy \\
\hline Mercury & *** & Mildew Resistant Additive in Paint Coatings \\
\hline Molybdenur & & Experimental Assembly, Stainless Steel Alloy, Lubricant \\
\hline Nickel & & Stainless Steel Wires Used for Seismic Restraint \\
\hline Niobium *⿻一 & & An Alloy of Depleted Uranium, Bullnose Surface \\
\hline Potassium & $\star \star \star$ & Environmental Background, Possible Historical \\
\hline Selenium & & Below a High Limit of Detection (100 ug/g) \\
\hline Silica *, & ** & $\begin{array}{l}\text { Aluminum and Stainless Stell Alloy, Paint Coating Additive, } \\
\text { RTF Sealant }\end{array}$ \\
\hline Silver & & Experimental Assembly, Solder \\
\hline Sodium ** & & Environmental Background \\
\hline Strontium & *** & Possible Historical Background or Bullnose Surface \\
\hline Thallium & & Below a High Limit of Detection $(30 \mathrm{ug} / \mathrm{g})$ \\
\hline Titanium* & & Pigment in the Chamber Surface Paint Coating \\
\hline Uranium & & Below a High Limit of Detection (70 ug/g) \\
\hline Vanadium & & Experimental Assembly \\
\hline Zinc & & Experimental Assembly, Aluminum Alloy \\
\hline
\end{tabular}




\subsection{Surface Swipes}

Surface swipe samples were taken after SQTS 05 on both the equipment door and personnel door frames to indicate the characteristics of airborne metals due to leakage past the gasket seals. These surface samples were taken of a white, powdery residue that formed across the inside frame of the door and across the gasket seal. The surface swipes were taken, over an area of approximately 100 square centimeters. These surface swipe samples were taken to indicate the characteristics of airborne metals due to leakage past the gasket seals. A mean of $88.4 \%$ of the particulates on the door frames were of a non-spherical morphology which indicates leakage quickly after the initial shot time. The personnel door frame also had 6 times more particulates larger than 100 microns in width when compared to the equipment door. This may reflect positively on efforts to seal in larger particles within the chamber at the equipment door. This information is similarly supported by the airborne metals information and carbon monoxide leak detection methods discussed below.

\subsection{Airborne Metals}

Area, non-personal, measurements for airborne metals, reflected in Table 10, were all taken at the Hinge Side during SQTS 04 and 05. Measurements for metals at the door were taken against the hinge side of the equipment door and also at 15 feet away from that point, both at a height of 4 feet above the floor ${ }^{1}$. The levels for aluminum taken during SQTS 04 were $226 \mu \mathrm{g} / \mathrm{m}^{3}$ at the door and $74.7 \mu \mathrm{g} / \mathrm{m}^{3}$ at a point 15 feet away. The reductions in exposure levels for aluminum, as well as copper and manganese, were reduced to a limit below the limit of detection for SQTS 05. Only iron was present at levels of $10.2 \mu \mathrm{g} / \mathrm{m}^{3}$ at the door and $2.86 \mu \mathrm{g} / \mathrm{m}^{3}$ at a point 15 feet away. Here the area air sampling for metals was yet another indicator of the success in improving the integrity of the Equipment Door's seal. A possibly unrelated, yet still interesting, question is brought up with the information in Table 13 as to why only iron was seen when aluminum concentrations within the chamber dust were at a concentration of at least three times higher than iron for SQTS 05. It has been theorized that this may be indicative of hot, high pressured air being forced across the mild steel deflection barriers and not necessarily reflecting a leak of the dust from within the chamber.

Personal measurements for airborne metals, reflected in Table 11, were taken as part of the re-entry procedures into the personnel door and vestibule during SQTS 04 and 05 . It should be noted that the information presented in Table 10 reflects area, non-personal, sampling and Table 11 presents personal sampling results of employees performing the re-entry procedures for SQTS 04 (57 and 55 minute sampling period) and 05 (57 and 56 minute sampling period). 
Taken from the information presented in Table 11, Employee 1 performed the entry into the chamber area while Employee 2 remained in the vestibule area during the entire sampling period, never entering the chamber. The mean personal exposure level for aluminum was $50.9 \mu \mathrm{g} / \mathrm{m}^{3}$ during the sampling periods for SQTS 04 and 05 . This exposure level is 255 times the beryllium Action Level and covers initial entry procedures only. Of greater interest is Employee 2 personal sampling results during SQTS 04. This individual obtained a personal sample result for manganese at $0.34 \mu \mathrm{g} / \mathrm{m}^{3}$ within the vestibule. Although manganese is test constituent at only trace levels, this is the only personal metals exposure within the range of the beryllium Action Level.

\subsection{Combining Metals Analysis With Leakage Potential}

Combining metals analysis and leakage results ${ }^{1}$ indicates the potential for a problematic personal exposure to metals external to the chamber unless modifications are made. Previous carbon monoxide monitoring indicates a leak potential at five locations: Camera Room, Short Chase, Long Chase, Equipment Door, and Personnel Door.. Metals analysis results show that virtually all metals within the chamber, even trace levels as alloys or on the chamber surfaces, can be accounted for in the dust analyses and therefore may be present wherever leaks may occur as both airborne and surface particulate. This consideration expands the potential for exposures to include the prefilter staging area during the removal and replacement of used pre-filters. Leaks from either the Equipment Door or the Personnel Door may also complicate re-entry and retrieval protocol in the attempt to control personal exposure levels and surface contamination control within the High Bay area as well.

Preliminary estimates have been made that attempt to link personal sampling information to metal concentrations within the bulk dust samples for an individual test. There are no protection factors used, only the use of minimum metal concentrations from Table 1 relative to the highest personal sampling results from Table 11. Results for personal exposure to copper from SQTS 04 were compared to the lowest bulk dust concentration during the same test with the intention of achieving a personal exposure level at the Be Action Level without the consideration an 8-hour Time Weighted Average. This rough estimate also presumes that $50 \%$ of the mass within the CFF chamber is not completely consumed. Within these guidelines, approximately 10 milligrams of beryllium per each $\mathrm{Kg}$ of mass within the chamber may lead to exposures during personnel door re-entry procedures above the $0.2 \mu \mathrm{g} / \mathrm{m}^{3}$ Action Level. Similar considerations should also be made for areas external to the chamber where previous carbon monoxide monitoring data indicates a leak potential: Camera Room, Short Chase, Long Chase, Equipment Door, and Personnel Door. 


\subsection{Recommendations}

2) Particle Size Selective Data Collection. There is a need to continue this metals analysis protocol and extend it into future tests at the CFF. Metals analysis should continue for all tests, however most important is the need to begin developing a data set for various levels of beryllium-related activities. This is best performed in conjunction with standard Industrial Hygiene sampling protocol. This will afford the ability to correlate personal exposure potential to the dynamics of a particular testing protocol and the inclusion of highly toxic materials as part of the experimental assembly.

3) Equipment Door and Personnel Door Considerations. Reduction in the leak rates at the Equipment Door were seen, and corroborated by an area metals sampling protocol, after efforts had been made to improve the Equipment Door's integrity and seal. The combined metals and carbon monoxide monitoring results support the recommendation that efforts to improve the seals at the Equipment Door should be continued to reduce the potential for leaks at these entry portals. Efforts should also be made for the Personnel Door to control the personal exposure potential in the vestibule. Further, it is recommended to install or connect a HEPA-filtered exhaust ventilation system for use within the vestibule area. This will also assist in maintaining a negative pressure for the 3-stage decontamination unit, sealed in place at the entry into the vestibule, that will be necessary for maintaining appropriate housekeeping during beryllium-related activities within the chamber.

4) Potential for Airborne and Surface Contamination. Previous carbon monoxide monitoring indicates a leak potential at five locations. The metals analysis results that show the potential for exposure outside of the chamber should also include the pre-filter staging area during the removal and replacement of used pre-filters. Metals analysis results show that virtually all metals within the chamber, even trace levels as alloys or on the chamber surfaces, can be accounted for in the dust analyses and therefore may be present wherever leaks may occur as both airborne particulate and surface contamination. Preliminary estimates based on existing SQTS data indicate that approximately 10 milligrams of beryllium per each kilogram of mass within the chamber may lead to personal exposures, during personnel door re-entry procedures, above the $0.2 \mu \mathrm{g} / \mathrm{m}^{3}$ Action Level for beryllium. The current re-entry procedures are only a preliminary indication of the potential for exposure during normal re-entry protocol that will include the disturbance of the chamber's dusty environment to retrieve experimental equipment before the water washdown occurs. Of great interest is the personal sample result for manganese at 0.34 $\mu \mathrm{g} / \mathrm{m}^{3}$ within the vestibule. Although manganese is a test constituent at only trace levels, this is the only personal sampling exposure for metals within the range of the beryllium Action Level of $0.2 \mu \mathrm{g} / \mathrm{m}^{3}$. 


\subsection{References}

1) Zalk, D., Non-Occupational Industrial Hygiene Monitoring Results for the Structural Qualification Test Series 01 - 05. May 30, 2001.

2) Zalk, D., Air monitoring during re-entry procedures for Structural Qualification Test Series 01. May 6, 2001

3) Zalk, D., Air monitoring during re-entry procedures for Structural Qualification Test Series 02. May 8, 2001

4) Zalk, D., Air monitoring during re-entry procedures for Structural Qualification Test Series 03. May 14, 2001.

5) Zalk, D., Air monitoring during re-entry procedures for Structural Qualification Test Series 04. May 17, 2001.

6) Zalk, D., Air monitoring during re-entry procedures for Structural Qualification Test Series 05. May 20, 2001

7) ACGIH Threshold Limit Values for Chemical Substances, 2001

8) Hinds, W.C., Aerosol Technology: Properties, Behavior, and Measurement of Airborne Particles. John Wiley and Sons, New York, 1982. 